\title{
Pakistan's two-stage monsoon and links with the recent climate change
}

\author{
Shih-Yu Wang, ${ }^{1,2}$ Robert E. Davies, ${ }^{1}$ Wan-Ru Huang, ${ }^{3}$ and Robert R. Gillies ${ }^{1,2}$ \\ Received 1 February 2011; revised 17 May 2011; accepted 27 May 2011; published 24 August 2011.
}

[1] Meteorological conditions related to the Pakistan floods of 2010 were examined in the context of monsoon dynamics and large-scale circulations. Case and climatological analyses suggest that summer precipitation in northern Pakistan comprises two distinct phases: (1) a premonsoon trough phase (July) whose rainfall is more episodic and intense, occurring prior to arrival of the monsoon trough, and (2) a monsoon trough phase (August) whose rainfall is persistent, yet less episodic, driven by northward migration of the monsoon trough. Analyses of conditional instability, moisture flux, and circulation features support a persistent increase in conditional instability during the July premonsoon trough phase, accompanied by increased frequency of heavy rainfall events. Conversely, evidence does not support intensification of the August monsoon trough phase. The increased convective activity during the premonsoon trough phase agrees with the projected increase in the intensity of heavy rainfall events over northern Pakistan. Largescale circulation analysis reveals an upper-level cyclonic anomaly over and to the west of Pakistan-a feature empirically associated with weak monsoon. The analysis also suggests that the anomalous circulation in 2010 is not sporadic but rather is part of a long-term trend that defies the typical linkage of strong monsoons with an anomalous anticyclone in the upper troposphere.

Citation: Wang, S.-Y., R. E. Davies, W.-R. Huang, and R. R. Gillies (2011), Pakistan's two-stage monsoon and links with the recent climate change, J. Geophys. Res., 116, D16114, doi:10.1029/2011JD015760.

\section{Introduction}

[2] The Pakistan floods of 2010 constitute an extreme hydrologic and sociologic event. At their height they submerged roughly $20 \%$ of Pakistan's land area, killing and injuring nearly 5,000 people directly, and displacing as many as 20 million (Singapore Red Cross, http://www.redcross.org. $\mathrm{sg} /$ The-Pakistan-Floods-Update.phtml). Economic impact to the region, comprising loss of life, infrastructure, agriculture and livestock, has been extreme (World Food Program, http:// documents.wfp.org/stellent/groups/public/documents/ena/ wfp225987.pdf). Though influenced by additional factors (e.g., snowmelt and water management practices), the floods were closely tied to an unusually heavy rainfall event. The July-September 2010 country-wide total was the highest since 1994 and sixth highest in the last 50 years [Pakistan Meteorological Department (PMD), 2010]. Most of the heavy rainfall occurred in July and August. The weather event leading to flash floods in 2010 began with a series of locally developed, intense rainstorms in July, followed by

\footnotetext{
${ }^{1}$ Utah Climate Center, Utah State University, Logan, Utah, USA.

${ }^{2}$ Department of Plants, Soils, and Climate, Utah State University, Logan, Utah, USA.

${ }^{3}$ Guy Carpenter Asia-Pacific Climate Impact Centre, City University of Hong Kong, Hong Kong.

This paper is not subject to U.S. copyright. Published in 2011 by the American Geophysical Union.
}

consecutive monsoon rains throughout the early half of August [Webster et al., 2011]. Synoptic analysis by Houze et al. [2011] pointed out that both the intensity and structure of the July rainstorms were abnormal to northern Pakistan. Due in part to other and myriad extreme events in the summer of 2010 , such as the Russian heat wave, questions have arisen as to whether or not the unusual 2010 Pakistan rainfall falls within the realm of climate variability, or is connected in some measure with global climate change [Marshall, 2010].

[3] Within existing literature, precipitation in Pakistan is partitioned into two seasons: (1) heavy summer rains in eastern Pakistan from monsoon currents; and (2) late winterearly spring rains due to western disturbances (or upperlevel short waves) [Kazi, 1951; Khan, 1993; Hussain and Lee, 2009]. The summer rains, taken from July to September, are considered monsoonal, i.e., associated with the monsoon trough, and comprise $50-75 \%$ of Pakistan's annual rainfall [Kazi, 1951; Kureshy, 1998]. Previous studies have noted that differing cloud systems, from the Bay of Bengal to the southeast and from the Arabian Sea to the south, contribute to the summer rains [Kazi, 1951; Khan, 1993]. In terms of variability, it is well established that intraseasonal variations of the South Asian monsoon trough, often referred to as the 30-60 day mode, have a profound impact on monsoon rains, not only in India but also over its northern boundaries [Chang and Krishnamurti, 1987; Goswami, 2005]. Fluctuations of the Eurasian teleconnection-propagating Rossby wave trains across Eurasia and 
2010
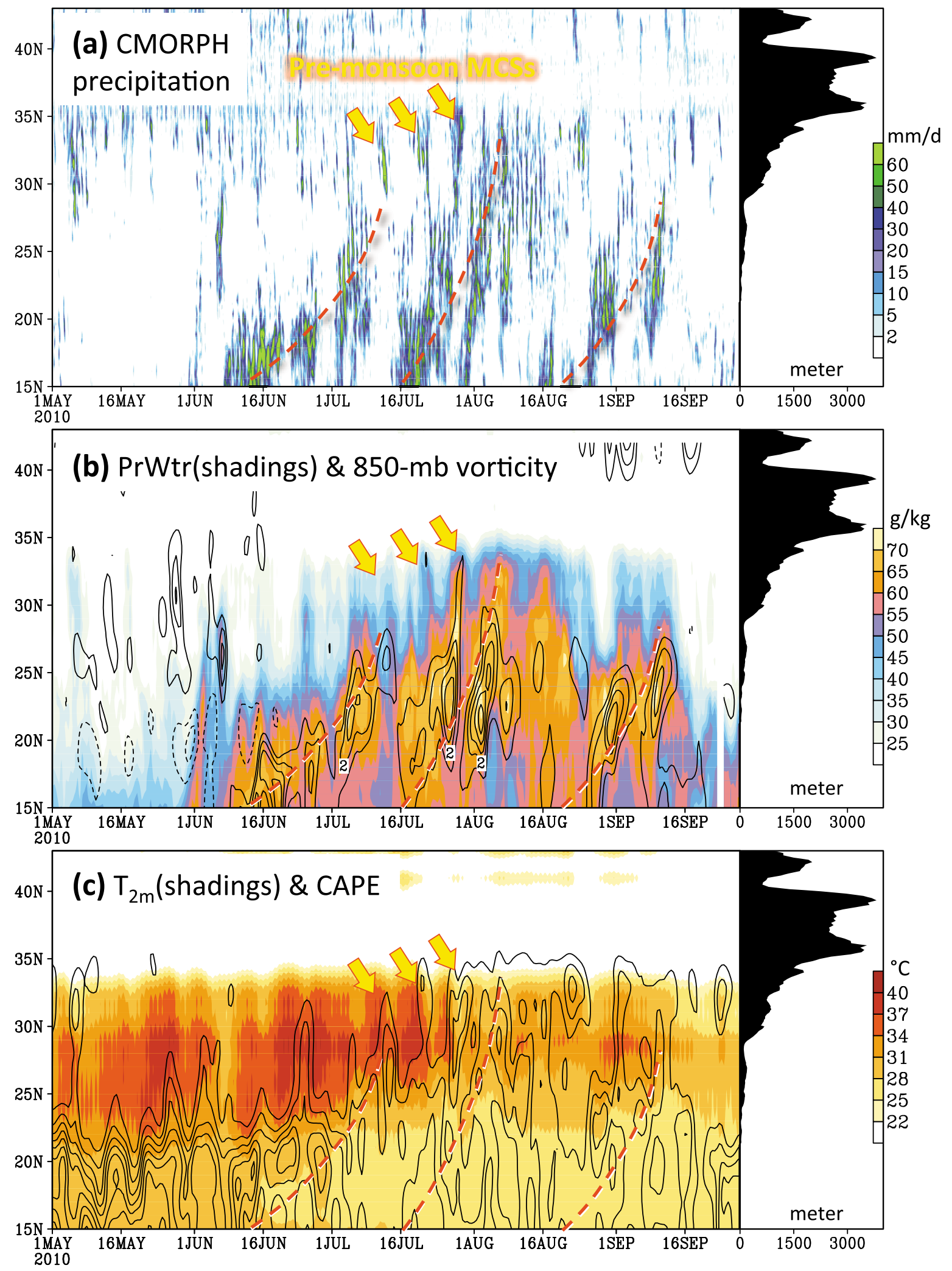

Figure 1. Latitude-time diagrams for (a) CMORPH $3 \mathrm{~h}$ precipitation, (b) precipitable water (shadings) and 850 mbar relative vorticity (contour interval $10^{-5} \mathrm{~s}^{-1}$ omitting zero and $-10^{-5}$ ), and (c) $\mathrm{T}_{2 \mathrm{~m}}$ (shadings) and CAPE (contour interval $300 \mathrm{~J} \mathrm{Kg}^{-1}$ beginning at 300) averaged between $70^{\circ} \mathrm{E}$ and $75^{\circ} \mathrm{E}$ from 1 May to 30 September 2010. Dashed lines indicate the three monsoon troughs. Yellow arrows indicate the three MCSs in July. Mean elevation across the analysis area is shown to the right of each panel. 
East Asia-also modulate the northern part of the Indian monsoon [Ding and Wang, 2007]. Moreover, summer rains in northern Pakistan can be triggered by monsoon depressions tracking northwest from the Bay of Bengal and into the monsoon trough [Muhammad, 2005; Yoon and Chen, 2005]. In 2010, several such monsoon depressions moved across India and enhanced moisture pooling in Pakistan during the late July rainstorms [Houze et al., 2011].

[4] With respect to climate change, previous studies predict an increase in precipitation and an enhancement in rainfall variability of the South Asian monsoon [Meehl and Washington, 1993; Intergovernmental Panel on Climate Change (IPCC), 2007]. Some observational studies find increasing trends in both the frequency and intensity of extreme rainfall events over India during the monsoon season in response to the warming trend [e.g., Goswami et al., 2006]. Other studies find decreasing trends in the frequency of monsoon depressions over the Bay of Bengal and the Arabian Sea during 1890-1999 [Singh, 2001; Patwardhan and Bhalme, 2001], inconsistent with an enhanced hydrological cycle in India hypothesized to have resulted from greenhouse warming [Patwardhan and Bhalme, 2001; Kripalani et al., 2003]. These conflicting results, together with the uncharacteristic rainstorms in 2010, raise a question on the role of climate change in the cause of heavy monsoon rains in northern Pakistan.

[5] In this paper we examine the monsoon conditions during the 2010 summer, with emphasis on the climatology of relevant quantities and their trends. We further investigate to what extent the trends can be associated with the climate system's internal variability versus an external forcing. The causes of the extreme floods are manifold and not our focus; mesoscale details and rainfall characteristics of the 2010 floods are referred to Houze et al. [2011] and Webster et al. [2011]. This study utilizes a recently released gridded precipitation data set with high spatial and temporal resolutions, which is introduced in section 2. The meteorological conditions, climatology, and trend analyses of the Pakistan monsoon are presented in section 3. Summary and some conclusions are given in section 4 .

\section{Data Sources}

[6] The Asian Precipitation-Highly Resolved Observational Data Integration Toward Evaluation (APHRODITE) [Xie et al., 2007], a gridded daily precipitation data set, is derived from rain gauges throughout the Monsoon Asia with a fine resolution $\left(0.5^{\circ}\right.$ longitude $\times 0.5^{\circ}$ latitude $)$ and is available for the period 1971-2007 (http://www.chikyu.ac. jp/precip/). The APHRODITE data set allows for an investigation of long-term daily precipitation over Pakistan, where stations with adequate periods of record are sparse. Other data include the $3 \mathrm{~h}$ Climate Prediction Center (CPC) Morphing technique precipitation (CMORPH) [Joyce et al., 2004] for the analysis of the 2010 event, the CPC Merged Analysis of Precipitation (CMAP) [Xie and Arkin, 1997] for the period 1979-2009, and the Tropical Rainfall Measuring Mission (TRMM)-based Lightning Imaging Sensor (LIS) 7 year climatology [Christian et al., 1999]. Due to the sparse and incomplete station records in Pakistan, we also adopted outgoing longwave radiation (OLR) (a proxy for convective activity) measured from polar orbiting satellites provided by the National Oceanic and Atmospheric Administration; the version used here is the uninterpolated daily data for the period 1974-2010.

[7] For meteorological variables we use the European Centre for Medium-Range Weather Forecasts' ERA40 reanalyses (1971-2002) [Uppala et al., 2005] and the ERAInterim reanalyses (1989 to present) [Uppala et al., 2008]. These two reanalyses provide $2 \mathrm{~m}$ air temperatures $\left(T_{2 m}\right)$ that are assimilated from surface observations. For data uniformity we reduced the horizontal and vertical resolutions of the ERA-Interim to be consistent with those of the ERA40 using bilinear interpolation. In addition, for verification purposes, three other global reanalyses were also used: (1) the National Centers for Environmental Prediction/ National Center for Atmospheric Research Global Reanalysis (NCEP1) [Kalnay et al. 1996], (2) the NCEP/Department of Energy Global Reanalysis II (NCEP2), the improved version of NCEP1 that included additional satellite-derived atmospheric information and newer physics schemes [Kanamitsu et al., 2002], and (3) the Modern Era Retrospective-analysis for Research and Applications (MERRA) developed by NASA, one that incorporates a synthesis of the current suite of satellite observations [Rienecker et al., 2011].

\section{Results}

\subsection{Case 2010 and the Climatology}

[8] The monsoon rainband movement and its association with the 2010 convective storms are displayed: in Figure 1a as the latitude-time diagram of CMORPH precipitation; and in Figure 1b as the ERA-Interim 850 mbar relative vorticity and column-integrated precipitable water, all averaged between $70^{\circ} \mathrm{E}$ and $75^{\circ} \mathrm{E}$, which contains northern Pakistan (see map in Figure 4b). Three northward moving monsoon troughs are readily visible in these meteorological fields. However, only the second reaches northern Pakistan (beyond $30^{\circ} \mathrm{N}$ ), elevating moisture and producing near-continuous rainfall there during the first half of August. Arrival of the second monsoon trough also increased the convective available potential energy (CAPE; Figure 1c contours) in northern Pakistan. By contrast, the three mesoscale convective systems (MCSs) responsible for the flash floods occurred during a drier and warmer period in July (arrow indicated), prior to the second monsoon trough's arrival; these features are discernable in the precipitable water and $T_{2 m}$ (Figures $1 \mathrm{~b}$ and $1 \mathrm{c}$ ). Moisture surges accompany each MCS (Figure 1b), apparently associated with passing synoptic disturbances as noted by Houze et al. [2011] and Webster et al. [2011]; these moisture surges are also evident in CAPE. Moreover, each of the MCSs occurred during the period when a series of midlatitude troughs intruded south, as revealed in the 250 mbar vorticity (Figure 2). Synoptic analysis (not shown) indicates that these troughs were coupled with the westward migrating depressions. Such a coupling between upper-level troughs and monsoon depressions signifies the tropicalmidlatitude interaction that is known to take place over this region [e.g., Chen et al., 2005]. Such a feature, together with warm temperatures over sloping terrain and strong moisture 
gradients, suggests a thermodynamically unstable atmosphere in July, prior to the monsoon trough's arrival in August.

[9] Figure 3a shows the CMORPH precipitation bandpass filtered with 30-60 days to examine the association between the rain strips and the northward advancing monsoon trough. The filtering uses the second-order Butterworth band pass. The filtered precipitation depicts three striking rainbands progressing northward, accompanied by three bands of cyclonic vorticity and high concentration of moisture, as revealed in the filtered vorticity and precipitable water (Figure 3b). These features are typical of the 30 60 day mode of the Indian monsoon [Krishnamurti and Subrahmanyam, 1982]. Comparing with Figure 1b, interactions of the monsoon trough with higher-frequency monsoon modes are also evident in the 10-20 day filtered vorticity and precipitable water (Figure 3c). Such interplay has been documented in the study of Indian monsoon variation [e.g., Krishnamurti and Ardunay, 1980]. Nonetheless, the July MCSs did not appear to connect with either the 3060 day monsoon trough or the 10-20 day monsoon mode, which never reached beyond $30^{\circ} \mathrm{N}$. On the other hand, the August rainfall episode was apparently influenced by the second monsoon rainband, which extended further north than the first trough.

[10] The meridional progressions of rainfall, moisture, and low-level vorticity shown in Figures 1 and 2 suggest that the common description of the summer monsoon in northern Pakistan as a single entity (i.e., July as the monsoon onset and August as the monsoon mature) may not be adequate. Instead, these summer rains comprise two distinct phases of development: (1) a premonsoon trough phase with drier, warmer air and episodic strong convection; and (2) a monsoon trough phase influenced by northward migrating monsoon troughs and associated humid, cooler air. Examining climatological $T_{2 m}$, dew point temperature $\left(T_{d}\right)$, and total precipitation in northern Pakistan from 1971 to 2010 (Figure $4 \mathrm{a}$ ), the warmest $T_{2 m}$ occurs in June with rapidly increased $T_{d}$ in response to the intrusion of moist air from the south. Then in July $T_{2 m}$ begins to decrease; $T_{d}$ reaches the seasonal maximum; and precipitation intensity peaks and is characterized by episodic features. In August, $T_{2 m}$ cools gradually while $T_{d}$ peaks and then decreases associated with declining rainfall.

[11] These climatological features are in good agreement with the 2010 analysis in Figure 1c, in which the July premonsoon trough phase comprises stronger instability and more intense convective systems. This can also be inferred from increased lightning frequency accompanying high values of both $T_{2 m}$ and $T_{d}$ in Figure $4 \mathrm{a}$, strong lightening activity being characteristic prior to the monsoon onset [e.g., Kodama et al., 2005]. By contrast, the August monsoon trough phase is characterized by less episodic rainfall of decreasing intensity and declining lightning activity. Further, the root-mean-square (RMS) of daily precipitation over the 1971-2010 period was computed; the difference between July and August is shown in Figure 4b. Over northern Pakistan, the RMS of daily precipitation is higher in July than in August, suggesting greater convective activity in the premonsoon trough phase, consistent with the observations in Figure 4a.

[12] Such differences in the monsoon phases are also evident in the 10 day mean patterns of the 250 mbar streamlines and precipitation in 2010 (Figure 5). During 1020 July (i.e., the rainstorm episode), northern Pakistan is situated north of the monsoonal anticyclone, under a deepened synoptic trough to the immediate west. This feature echoes the upper-level "short waves" influence on rainfall [e.g., Khan, 1993]. Low-level circulations (850 mbar) show that southwesterly flows prevail deeply inland over northern Pakistan, reflecting the moisture source of the MCSs. During 1-11 August (i.e., beginning of the monsoon trough episode), the monsoonal anticyclone matures and migrates north, completely covering northern Pakistan, while at 850 mbar an enhanced monsoon trough migrates toward northern Pakistan, as outlined by the red dotted line in Figure 5d. Corresponding climatological analysis reveals a similar situation in terms of the transition from trough to ridge in the upper troposphere (Figures 6a and 6b), while the low-level flows depict a seasonal monsoon trough during both phases (Figures $6 \mathrm{c}$ and $6 \mathrm{~d}$ ). The differences in the upper-level circulation between year 2010 and the climatology are wave-like; this will be discussed later.

[13] It is worth noting that the convective systems developing during these two phases of the monsoon are distinctly different. This is seen in the TRMM Precipitation Radar (PR) and Visible and Infrared Scanner (VIRS) images in Figures 5e and 5f, obtained from the Japan Aerospace Exploration Agency's TRMM web page at http://sharaku. eorc.jaxa.jp/trmm/RT/index_e.html. These two snapshots of the precipitation systems, taken respectively on 21 July and 7 August, show a squall line type of organized convection with trailing stratiform rainfall typical to those under the influence of synoptic waves (Figure 5e), in contrast to the air mass type of convection that is scattered and disorganized (Figure 5f). Also noteworthy is the difference in cloud coverage suggesting stronger ascending motion associated with the 21 July MCS (hence stronger subsidence outside the MCS) than the 7 August case.

\subsection{Trends}

[14] The identification of two distinct phases in the northern Pakistan monsoon, attributable to separate environmental conditions, suggests separate analysis for each phase. Mean precipitation of both the July premonsoon trough phase (Figure 7a) and the August monsoon trough phase (Figure $7 \mathrm{~b}$ ), averaged in the domain outlined in Figure $3 \mathrm{~b}$ over the past 40 years, shows virtually no tendency (orange bars and line). This is consistent with the fact that the summer rainfall in 2010, albeit extreme, ranks only sixth highest in observational history $[P M D, 2010]$. However, the convective nature of the premonsoon trough phase suggests the possibility that the unstable environment may be enhanced owing to post-1970 global warming, warming also evident in northern Pakistan (Figures 7a and $7 \mathrm{~b}$ ). To examine, we analyzed the frequency of intense precipitation - by computing the occurrences of grid-scale daily precipitation exceeding $5 \mathrm{~mm}$ (i.e., one standard deviation of the monthly mean) and then averaging the occurrences within the analysis domain (see Figure 4b). The frequency reveals a substantial upward trend in July (Figure 7a, blue bars and line), but shows only a weak trend in August (Figure 7b). A significance test of the trends is given in the caption, while trends without 2010 are overlaid as cyan dashed line (apparently 2010 did not alter the trend). Moreover, the contrast 


\section{PrWtr(shadings) \& 250-mb vorticity}

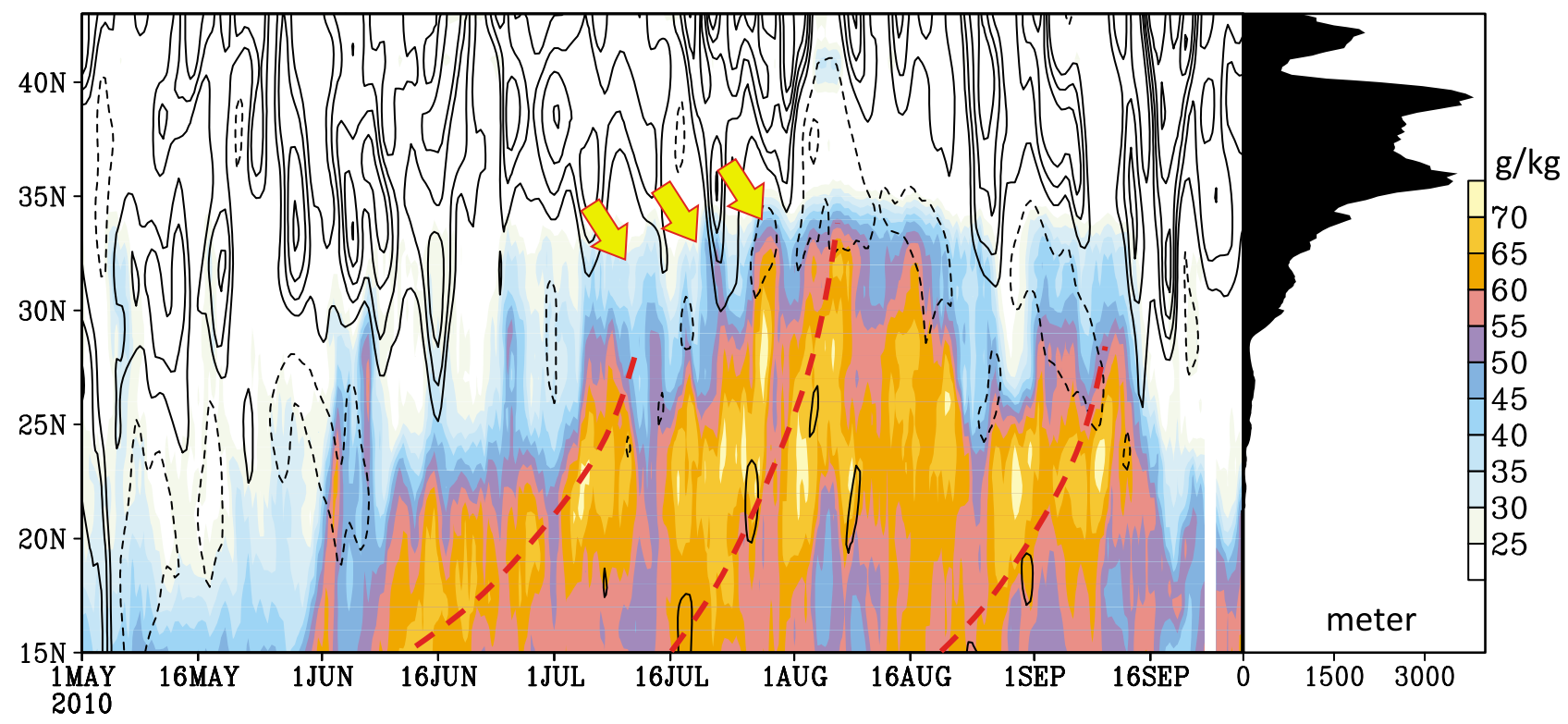

Figure 2. Same as Figure $1 \mathrm{~b}$ but for 250 mbar relative vorticity (contours; interval $2.5 \times 10^{-5} \mathrm{~s}^{-1}$ omitting zero). Yellow arrows indicate the three MCSs during July 2010 as defined in Figure 1a.

between trends in the mean precipitation versus the frequency of intense precipitation signifies an overall increase in rainfall intensity, which links to enhanced instability. This feature is particularly pronounced in the premonsoon trough phase of July.

[15] There may also be concerns about data quality and the domain averaging approach, such as those raised by Ghosh et al. [2009] on trends in the Indian monsoon. Thus, we further analyzed daily OLR derived from satellite observations. Using $220 \mathrm{~W} \mathrm{~m}^{-2}$ as a threshold value to depict intense precipitation (as was defined by Zhang [1993] for strong tropical convection), the frequency of grid-scale OLR lower than $220 \mathrm{~W} \mathrm{~m}^{-2}$ was computed. As shown in Figure $7 \mathrm{c}$, the frequency of deep convection (i.e., OLR $-220 \leq 0$ ) reveals a significant uptrend (blue bars and line) consistent with the APHRODITE analysis. Meanwhile the July mean OLR exhibits a slight uptrend (orange bars and line) reflecting warming and/or less sustained convection. This result supports the observation that precipitation intensity in July has increased, even though the mean amounts have not changed significantly. Likewise, August OLR shows a similar, yet insignificant tendency toward enhanced convection (Figure 7d).

\subsection{Role of Internal Variability}

[16] It has been suggested in the press that the monsoon trough has extended increasingly northward in recent decades, that this may have contributed to the 2010 flooding, and that this may be attributable to climate change [Marshall, 2010]. Evidence for such a northward extension, however, is absent from the literature (to our knowledge), although climate modeling points to an overall expansion of the South Asian monsoon [IPCC, 2007]. To investigate, we constructed latitude-time cross sections of 5 day mean precipitation, averaged over $70^{\circ} \mathrm{E}-75^{\circ} \mathrm{E}$, from 1 July to 31 August for each year of 1979-2009, using the CMAP data.
The result (Figure 8) reveals pronounced decadal and interannual variabilities in the monsoon rainbands. The most recent maximum of the monsoon's northward extension occurred in 2006, followed by a failed monsoon in 2009 [Krishnamurti et al., 2010]. By computing the area mean rainfall over three latitudinal zones $\left(20^{\circ} \mathrm{N}-25^{\circ} \mathrm{N}, 25^{\circ} \mathrm{N}-30^{\circ} \mathrm{N}\right.$, and $30^{\circ} \mathrm{N}-35^{\circ} \mathrm{N}$ ), and low-pass filtering at 7 years, it is shown that rainfall variations in each latitudinal zone correspond to one another and that the northern Pakistan rainfall and its northward extension are both in close association with the strength of the Indian monsoon south of $25^{\circ} \mathrm{N}$. However, there is no evidence suggesting that the northward extension of the monsoon has increased, at least during the last 31 years; instead, the amplification in the north $\left(30^{\circ} \mathrm{N}-35^{\circ} \mathrm{N}\right)$ seems to respond to the marked quasi-decadal variability characterizing the Indian monsoon.

[17] Earlier studies [e.g., Krishnan and Sugi, 2003] have noted a significant association of the Indian monsoon with the Pacific Decadal Oscillation (PDO), in the sense that a coherent inverse relationship exists between the all-Indian monsoon rainfall and the North Pacific sea surface temperature fluctuations. Recent studies [e.g., Wang et al., $2009,2011]$ report an increase in the quasi-decadal variability in the PDO with an increasing tropical loading. Based on these findings, the marked quasi-decadal variability in rainfall (Figure 8) may be reflective of the PDO's impact on the Indian monsoon (though we made no attempt to reinvestigate these features). It appears that, while the 2010 monsoon indeed extended to the far north $\left(\sim 35^{\circ} \mathrm{N}\right.$; Figure 1a), such a northward extent is within the realm of internal climate variability.

\subsection{Role of Climate Change}

[18] Since mean precipitation amounts in northern Pakistan reveal no trends, we focus the following analysis on the 

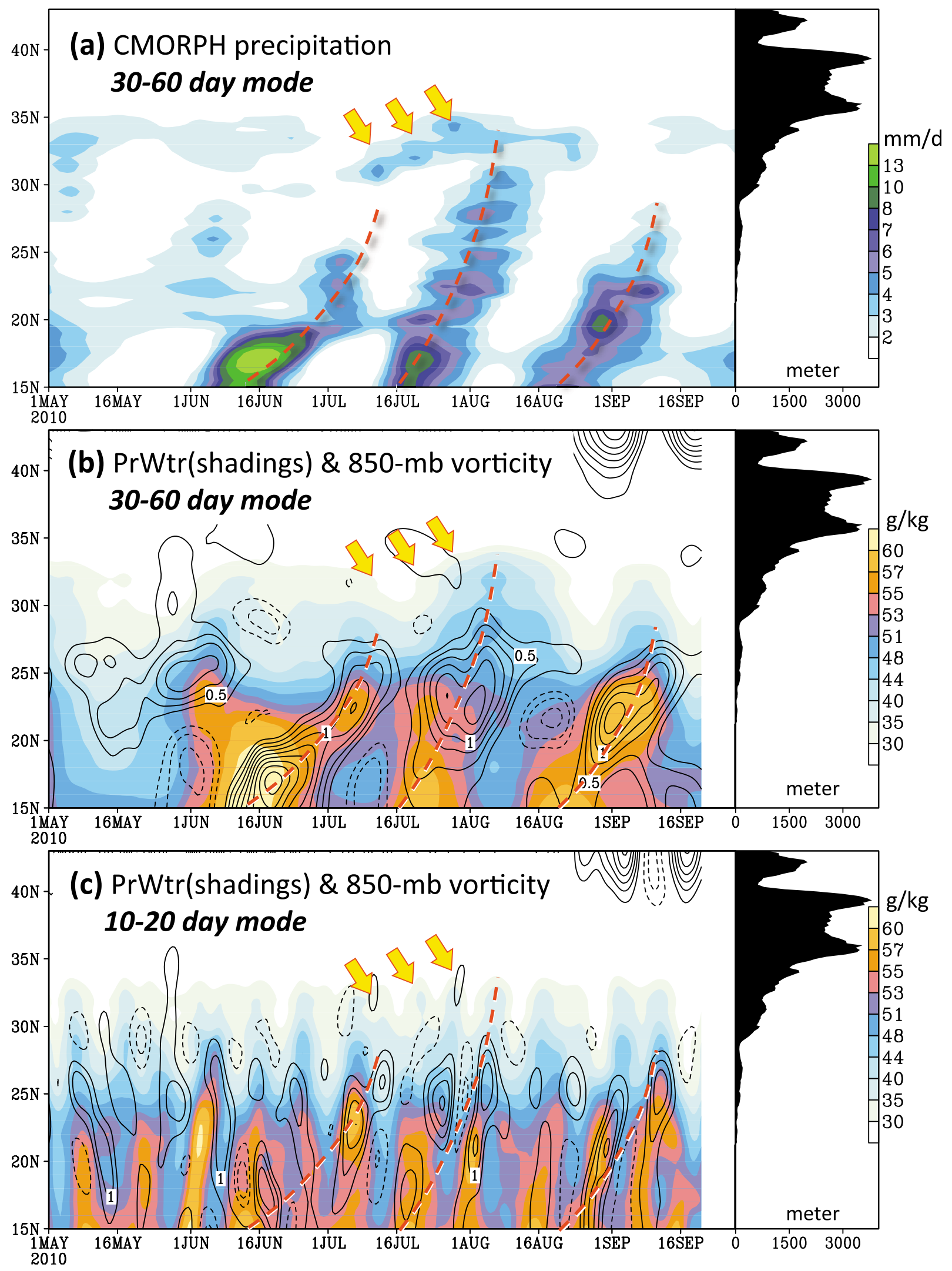

Figure 3. Same as Figure 1 but for the (a and b) 30-60 day band-pass filtering and (c) 10-20 day bandpass filtering of precipitable water and 850 mbar vorticity. The seasonal means of all fields are included. 


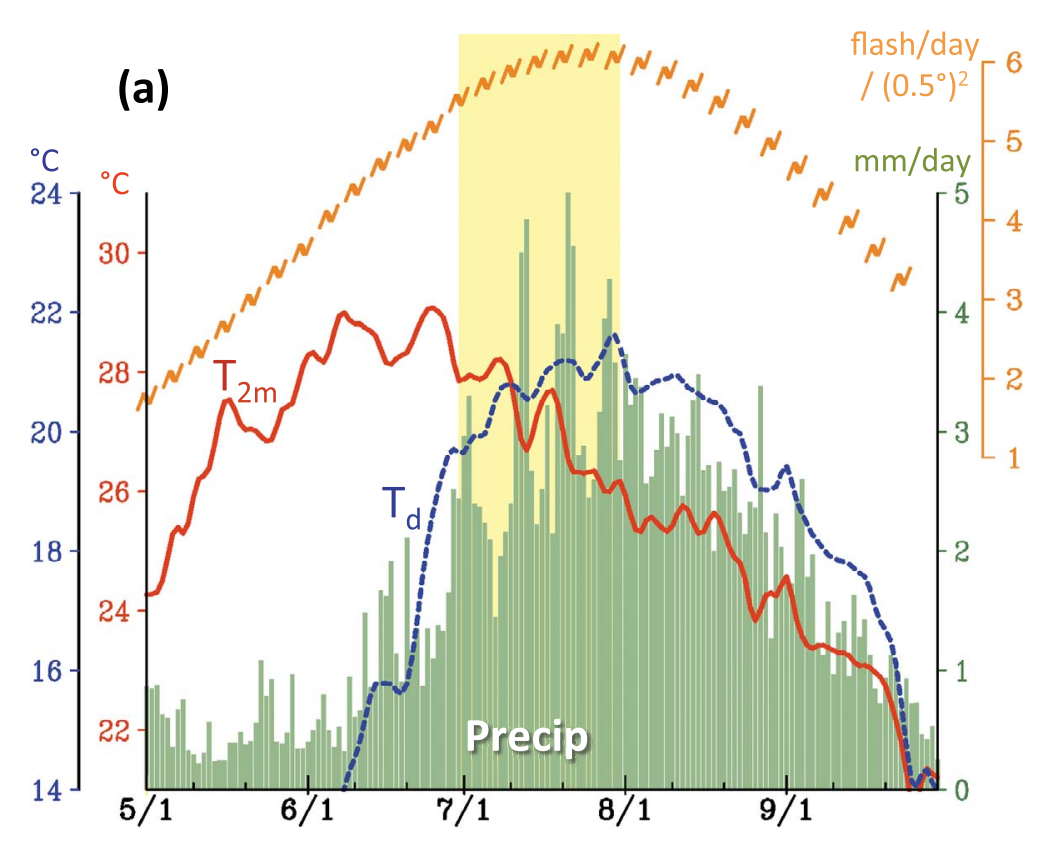

\section{(b) Differential precipitation RMS}

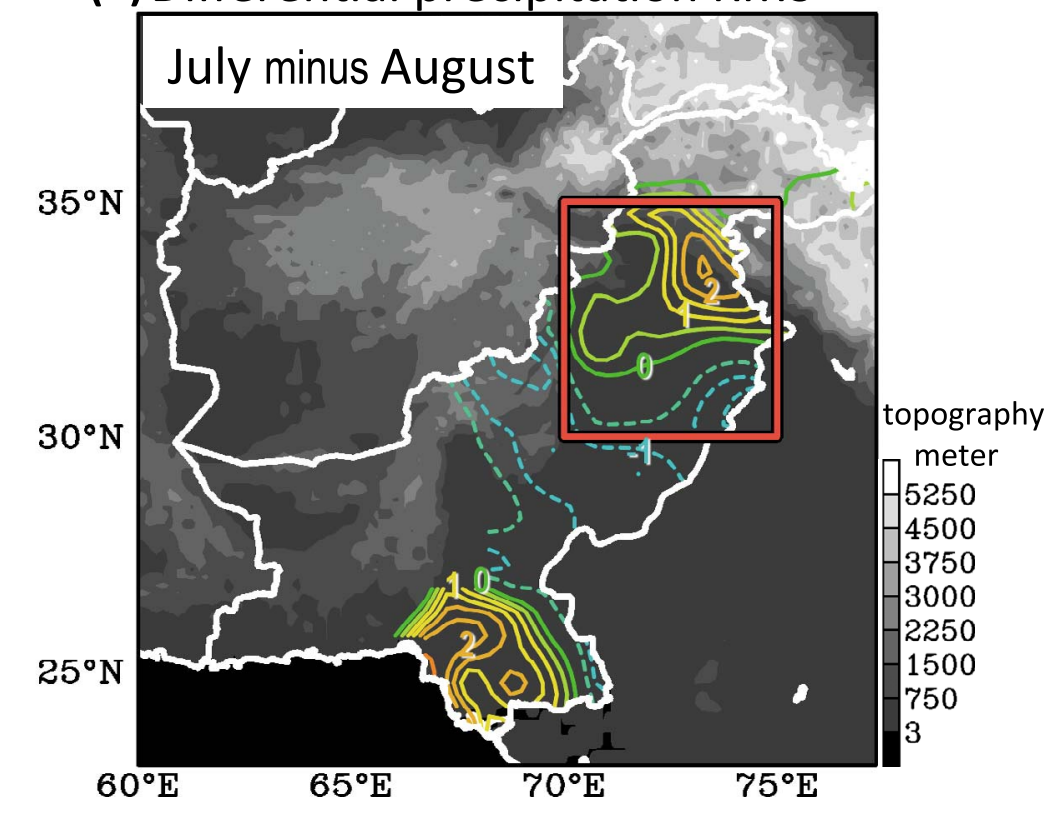

Figure 4. (a) Climatological means (1971-2009) of $T_{2 m}$ (red), $T_{d}$ (blue), precipitation (green bars), and lightning frequency (orange lightning symbols; plotted every 5 days) over northern Pakistan within the domain outlined in Figure 4b. The premonsoon phase is indicated by a light yellow strip. (b) Differences in the daily precipitation root-mean-square (RMS; contour interval $0.5 \mathrm{~mm} \mathrm{~d}^{-1}$ ) over Pakistan between July and August during the period 1971-2009 overlaid with the topography (shadings).

observed increase in convective activity. The atmospheric instability, especially during the premonsoon trough phase, is examined by the lapse rate of equivalent potential temperature $\left(\theta_{e}\right)$,

$$
\theta_{e}=T_{e}\left(\frac{p_{0}}{p}\right)^{\frac{R_{d}}{c_{p}}} \approx\left(T+\frac{L_{v}}{c_{p}} r\right)\left(\frac{p_{0}}{p}\right)^{\frac{R_{d}}{c_{p}}}
$$

where $T_{e}$ is equivalent temperature, $T$ is air temperature, $p$ is pressure and $p_{0}$ is standard reference pressure (1000 mbar), $R_{d}$ is specific gas constant, $c_{p}$ is specific heat of dry air, $L_{v}$ is latent heat of evaporation, and $r$ is mixing ratio. The lapse rate, denoted as $\frac{d \theta_{e}}{d p}$, is shown in Figure 9a with the climatological mean removed (shadings). A marked increase in $\frac{d \theta_{e}}{d p}$ is observed in the lower troposphere associated with a corresponding decrease in the upper troposphere. This suggests 

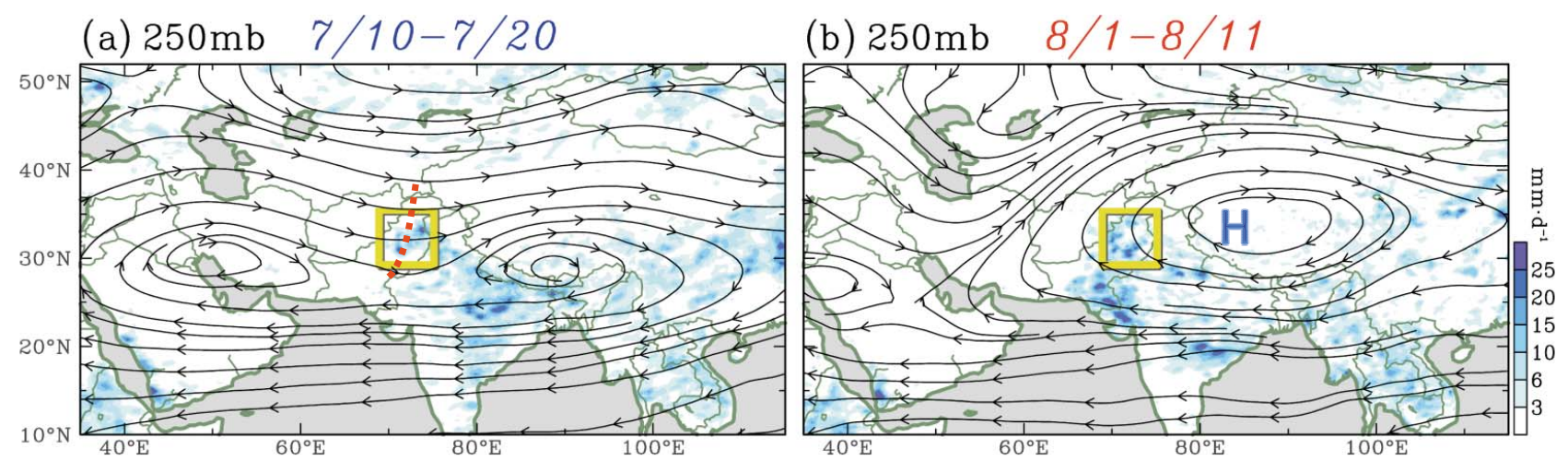

(c) $850 \mathrm{mb}$

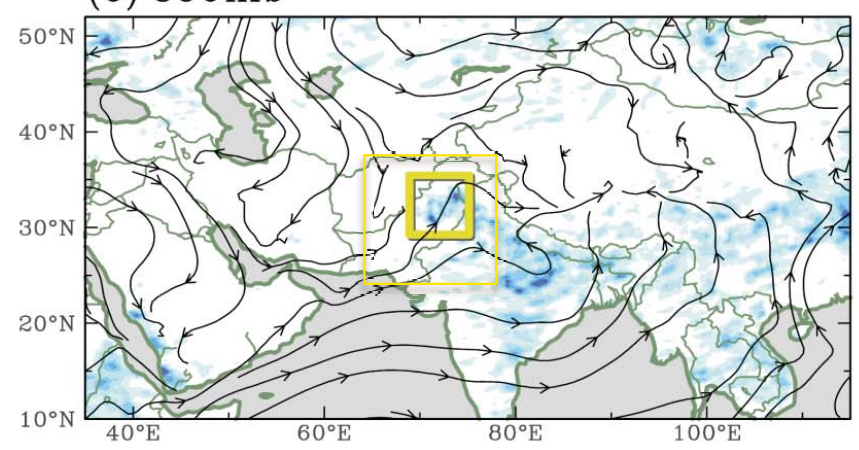

(d) $850 \mathrm{mb}$

(e) July 21 - 21UTC

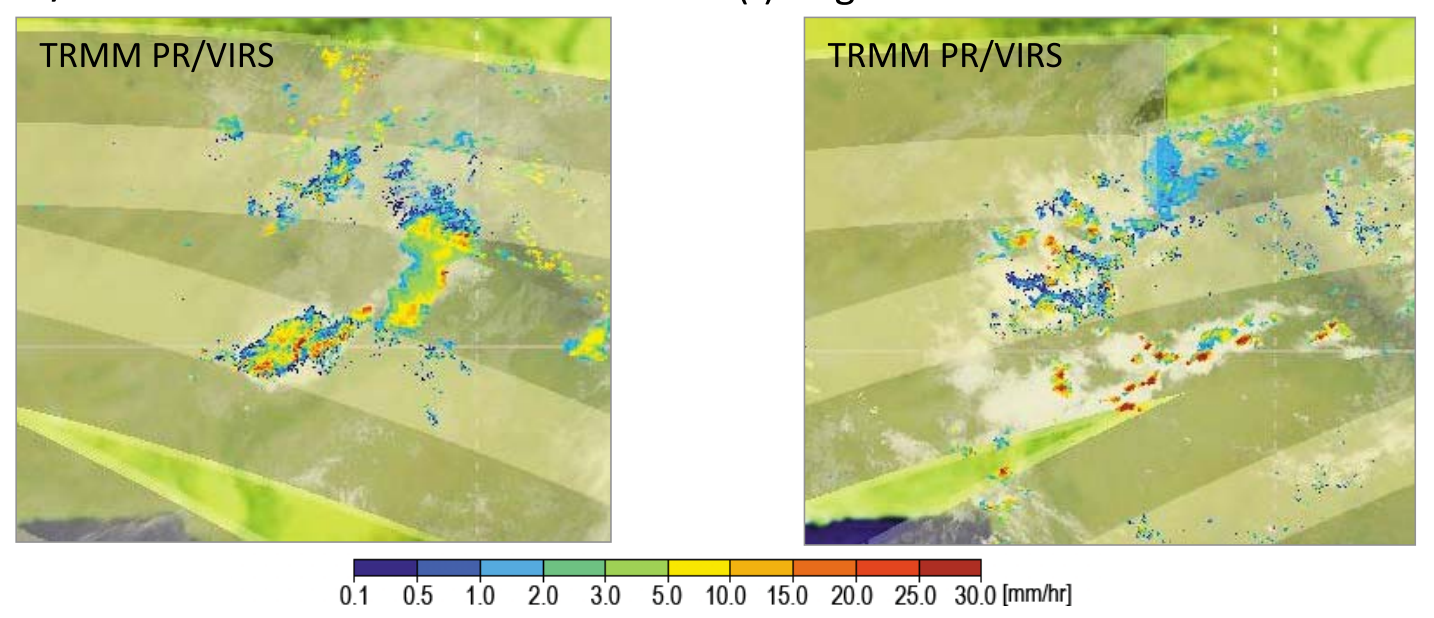

Figure 5. Streamlines at $250 \mathrm{mbar}$ and the CMORPH precipitation (shadings) averaged in (a) 10-20 July and (b) 1-11 August 2010. (c and d) The corresponding 850 mbar streamlines. Northern Pakistan is outlined by the yellow box. TRMM PR (rain) and VIRS (cloud) images over Pakistan (light yellow box in Figure 5c) at (e) 2100 UTC 21 July and (f) 0900 UTC 7 August. Red dashed lines in Figures 5a and $5 \mathrm{~d}$ indicate the synoptic-scale trough and the monsoon trough, respectively. The letter " $\mathrm{H}$ " in Figure $5 \mathrm{~b}$ indicates the monsoon anticyclone.

an overall increase in conditional instability, as well as potential instability for convective storms (commonly defined as the difference in $\theta_{e}$ between $850 \mathrm{mbar}$ and $500 \mathrm{mbar}$ ). In other words, additional moisture as seen in the increased $T_{d}$ in Figure $7 \mathrm{a}$, combined with surface warming over sloping terrain, may have enhanced conditional instability and, in turn, have increased the chance for stronger convective precipitation events. Such a situation is also observed in the August monsoon trough phase (Figure 9b), though the con- trast of $\frac{d \theta_{e}}{d p}$ anomalies between lower and upper troposphere is not as apparent as in July, except in the last decade. This recent enhancement of $\frac{d \theta_{e}}{d p}$ nonetheless coincides with the post-2000 increase in the frequency of intense precipitation (Figure 7b, after 2000). Because data quality has been an issue for climate analysis in this region, we also analyzed $\frac{d \theta_{e}}{d p}$ anomalies using MERRA, NCEP2, and NCEP1. The result (auxiliary material Figure S1) shows that, while different reanalyses reveal different details in $\frac{d \theta_{e}}{d p}$ anomalies, owing to 

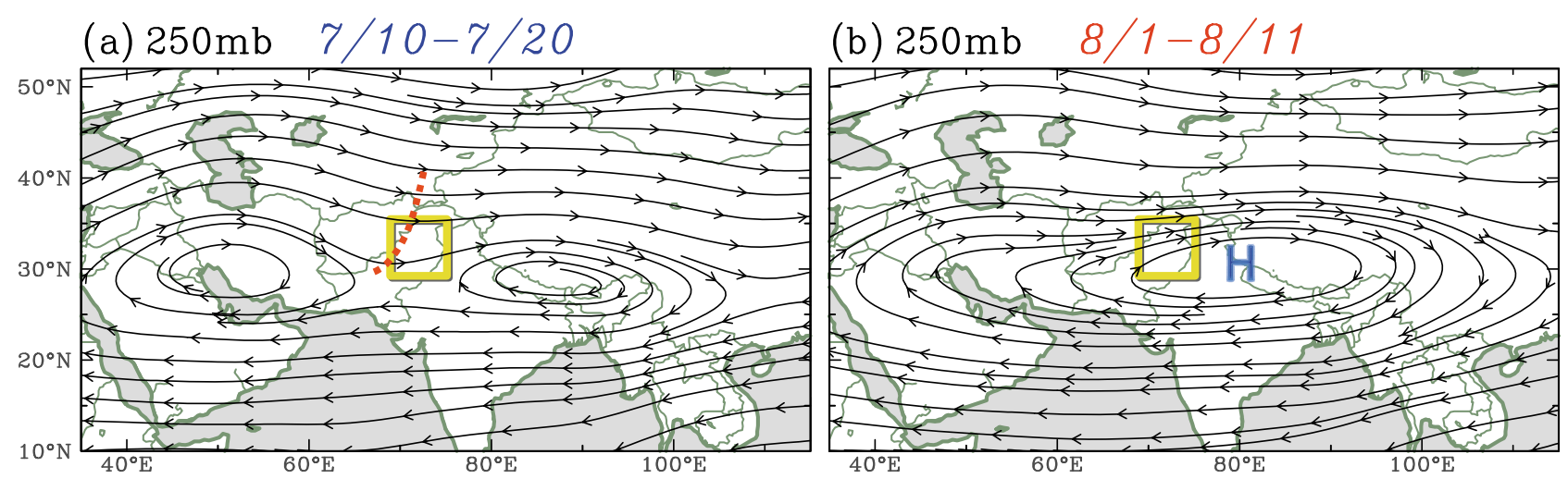

(c) $850 \mathrm{mb}$

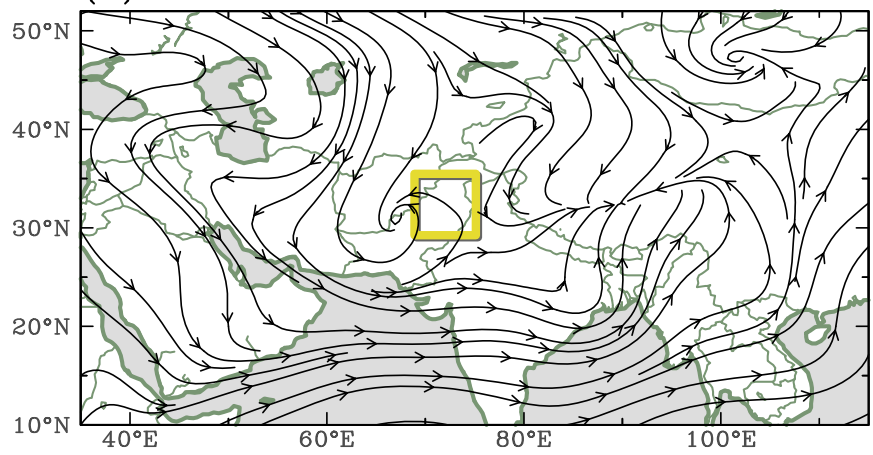

(d) $850 \mathrm{mb}$

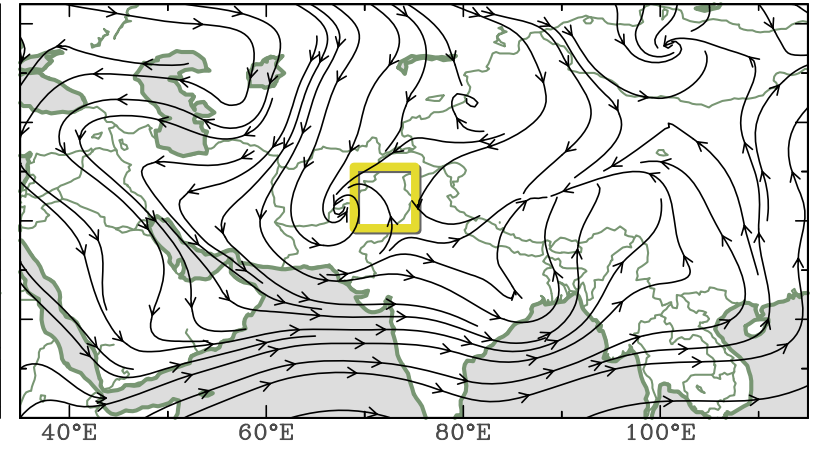

Figure 6. Climatological mean streamlines at 250 mbar averaged during (a) 10-20 July and (b) 1-11 August. Red dashed line in Figure $6 \mathrm{a}$ indicates the synoptic-scale trough and " $\mathrm{H}$ " in Figure $6 \mathrm{~b}$ indicates the monsoon anticyclone. (c and d) Same as Figures $6 \mathrm{a}$ and $6 \mathrm{~b}$ but for 850 mbar.

the various resolutions and assimilation systems, all of the data sets agree upon an overall trend toward steeper $\frac{d \theta_{e}}{d p}$, and that the increase in conditional instability is more pronounced in July than in August. ${ }^{1}$

[19] Sustained convection usually requires low-level convergence of moisture fluxes acting on convective instability. Thus, column water vapor flux was also computed,

$$
\vec{Q}=\int_{p s}^{300 m b}(q \vec{V}) d p
$$

where $q$ is specific humidity and $\vec{V}$ is tropospheric winds, as well as its divergence, $\nabla \cdot \vec{Q}$. Climatologically, water vapor flux over northern Pakistan is convergent in July (Figure 9c) but divergent in August (Figure 9d); this again supports the stronger convective activity in the premonsoon trough phase (see Figure 4). However, despite increasingly humid summers in northern Pakistan and the fact that stronger moisture convergence did occur in July 2010, trends in $\nabla \cdot \vec{Q}$ are insignificant in both July and August. To investigate changes in the ambient circulation that may control variations in $\frac{d \theta_{e}}{d p}$ and $\nabla \cdot \vec{Q}$, relative vorticity anomalies over northern Pakistan were computed and overlaid with Figures 9a and 9b (contours). There is no clear indication of increased/decreased low-level vorticity (i.e., the monsoon trough); in fact, the negative vorticity

\footnotetext{
${ }^{1}$ Auxiliary materials are available in the HTML. doi:10.1029/ 2011JD015760.
}

anomalies prevailing in the recent decade suggest a weakened monsoon trough, which would seem inconsistent with the increased frequency of intense precipitation.

\subsection{Dynamical Implications}

[20] It is well known that strong monsoons over India and Pakistan occur in association with an enhanced upper-level anticyclone and an easterly jet, as reviewed by Webster [2006]. To compare this feature with the 2010 anomalies, we use the domain-averaged monthly OLR over northern Pakistan (domain as in Figure 4b), subtracted from $235 \mathrm{~W} \mathrm{~m}^{-2}$ (to approximate rainfall) and regressed with the 200 mbar geopotential height through 1974-2010. The regression pattern (Figure 10a) depicts an anticyclone over and to the west of northern Pakistan, consistent with the literature. However, the July 2010 circulation anomalies reveal a marked cyclonic cell over northern Pakistan (Figure 10b), rather than an anticyclone as has been the case for strong monsoons. Noteworthy is the robust anticyclone over Eurasia that is linked to the Russian heat wave. Both the cyclonic and anticyclonic anomalies are embedded in a series of short waves resembling the so-called circumglobal teleconnection, i.e., Rossby wave trains with a zonal wave number-5 structure excited in the jet stream waveguide [Hoskins and Ambrizzi, 1993; Branstator, 2002]. Schubert et al. [2010] proposed that the heat wave-inducing anticyclone might enhance the cyclonic circulation downstream through Rossby wave energy dispersion. It is known that the monsoon in northern India is closely associated with the 
July

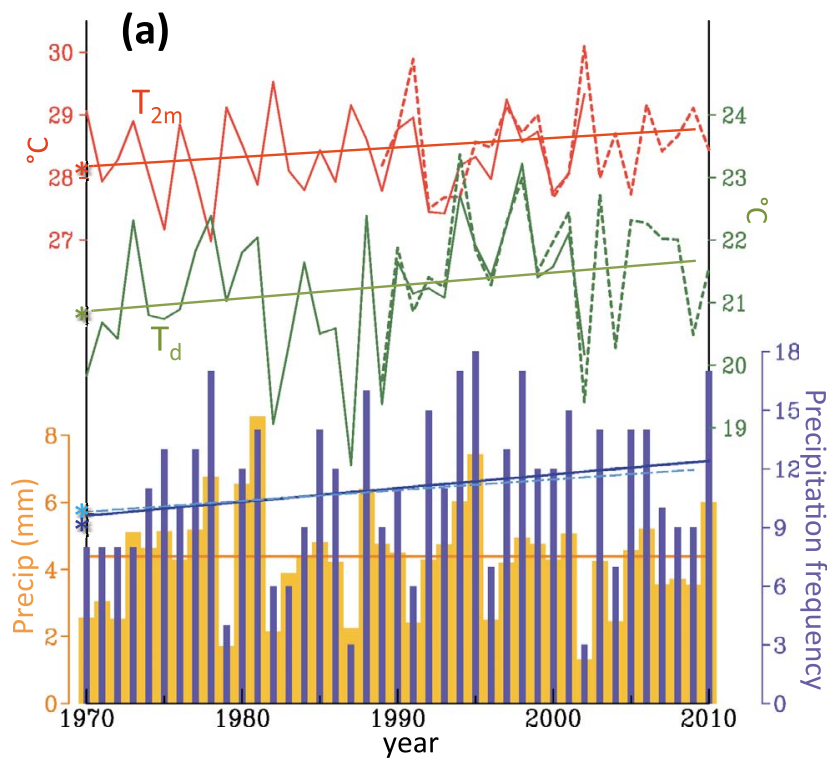

(c) OLR (July)

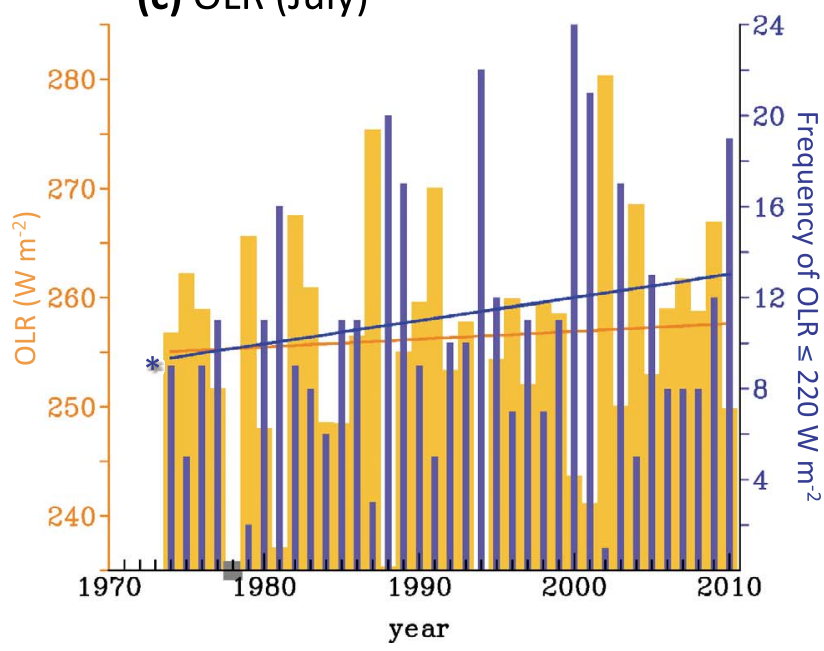

August

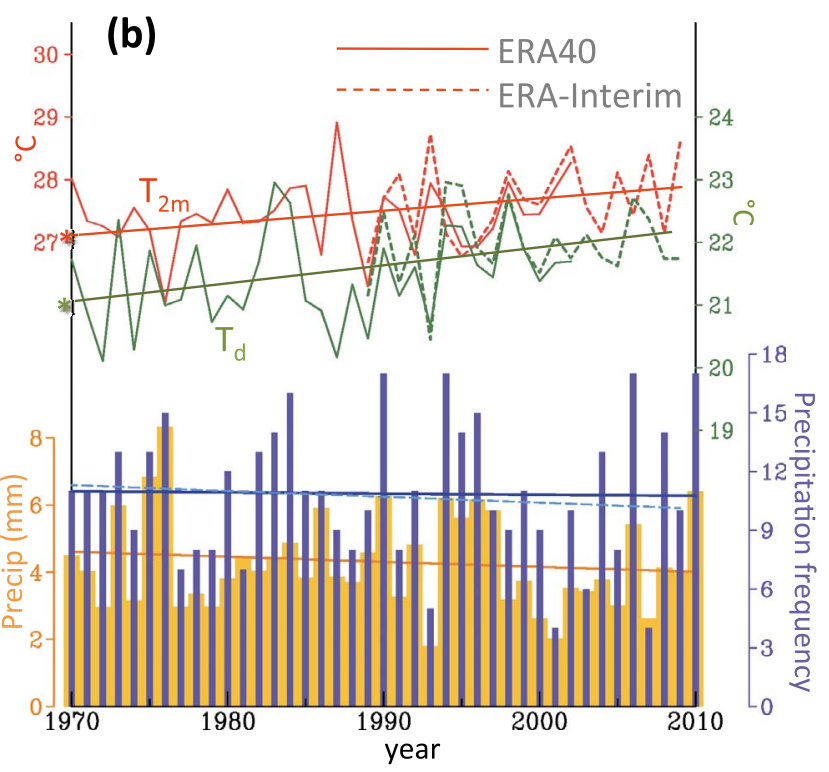

(d) OLR (August)

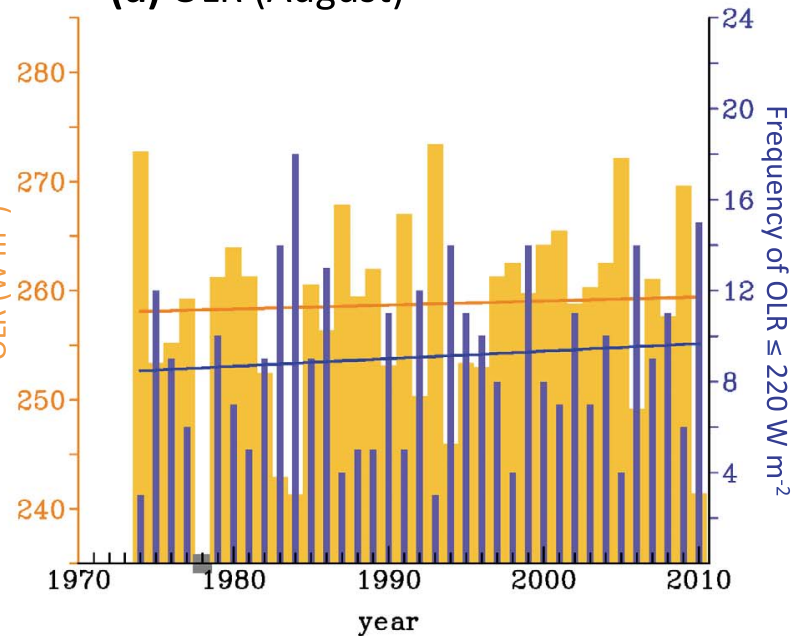

Figure 7. Monthly mean $T_{2 m}$ (red line), $T_{d}$ (green line), precipitation (orange bar), and frequency of intense precipitation (blue bar) over northern Pakistan (domain as in Figure 3b) in (a) July and (b) August, overlaid with linear trends. Dashed $T_{2 m}$ and $T_{d}$ lines indicate data derived from ERA-Interim (1989-2010). (c and d) Same as Figures 7a and 7b but for mean OLR (orange bar) and frequency of OLR$220 \mathrm{Wm}^{-2} \leq 0$ (blue bar); note that 1978 has no data. Trends that are significant at the $99 \%$ confidence interval (CI) are indicated by a star to the left, based on Student's $t$ test. Trends without a star are considered insignificant (i.e., $<99 \%$ CI). Trends without the inclusion of 2010 are shown as cyan dashed lines in Figures $7 \mathrm{a}$ and $7 \mathrm{~b}$. Temperature trends are computed from averages of the overlapping ERA40 and ERA-Interim data.

circumglobal teleconnection [e.g., Ding and Wang, 2005; Wang et al., 2010], though this association is based on the fact that strong monsoons are coupled with anticyclonic anomalies aloft, rather than a cyclonic anomaly as was in 2010.

[21] Such a discrepancy in the subtropical circulations is intriguing. As illustrated by Ding and Wang [2005], the upper-level anticyclone, coupled with strong monsoons, has a tropical "baroclinic" structure (i.e., vertically reversed), whereas the rest of the Eurasian wave train features a barotropic structure (i.e., vertically uniform). The 2010s cyclonic anomaly near northern Pakistan resembles the latter, as can be inferred from Figure 5, and subsequently enhances southerly water vapor flux. This feature corresponds to the abnormal moisture supply and lifting mechanism found in the July rainstorms [Houze et al., 2011]. The coupling of the monsoonal southerlies and the upper-level cyclonic flows also suggests a strong tropical-midlatitude 


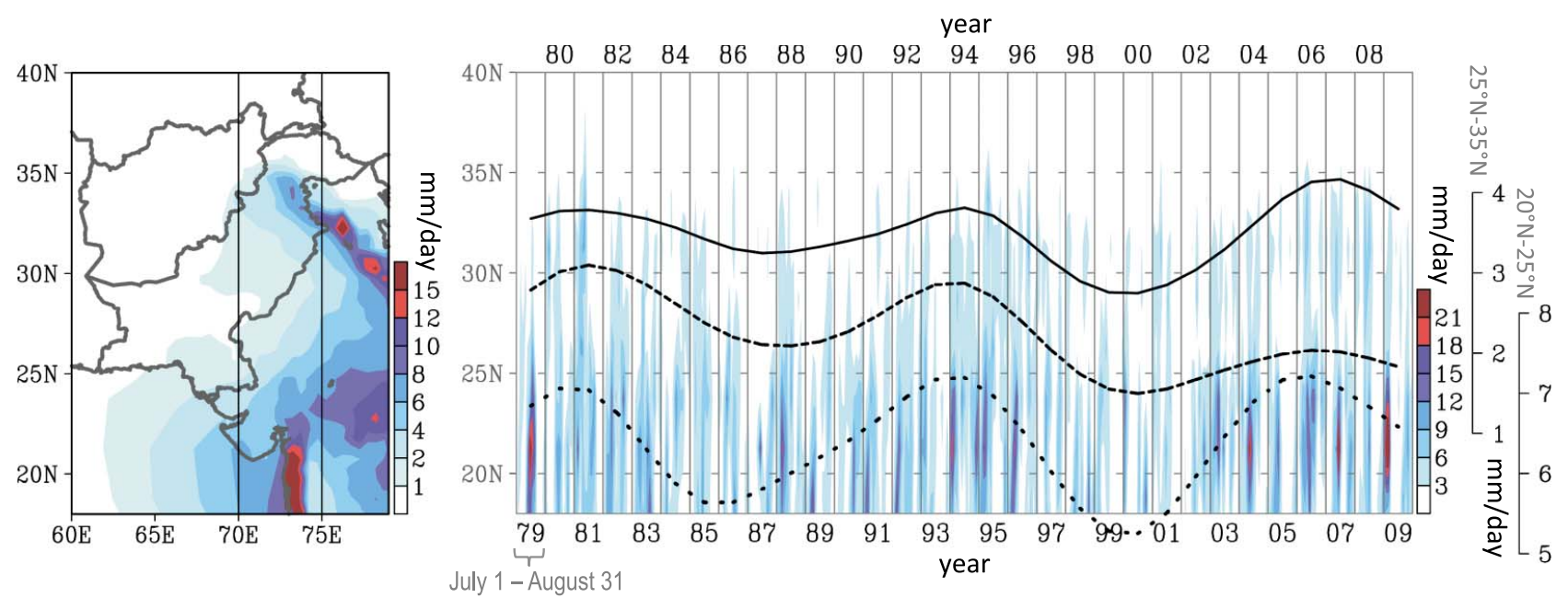

Figure 8. (right) Latitude-time diagrams of pentad mean precipitation (CMAP) averaged within $70^{\circ} \mathrm{E}-$ $75^{\circ} \mathrm{E}$ during the period 1 July 1 to 31 August for each year from 1979 to 2009. Precipitation time series averaged within $30^{\circ} \mathrm{N}-35^{\circ} \mathrm{N}$ (solid line), $25^{\circ} \mathrm{N}-30^{\circ} \mathrm{N}$ (dashed line), and $20^{\circ} \mathrm{N}-25^{\circ} \mathrm{N}$ (dotted line), lowpass filtered by 7 years, are overlaid. The precipitation scales corresponding to their latitude zone are given at the right (i.e., the rainfall range within $20^{\circ} \mathrm{N}-25^{\circ} \mathrm{N}$ is $5-8 \mathrm{~mm} / \mathrm{d}$; the rainfall range within $25^{\circ} \mathrm{N}-35^{\circ} \mathrm{N}$ is $1-4 \mathrm{~mm} / \mathrm{d}$ ). (left) The geographical distribution of mean July-August rainfall for comparison purposes.

(a)

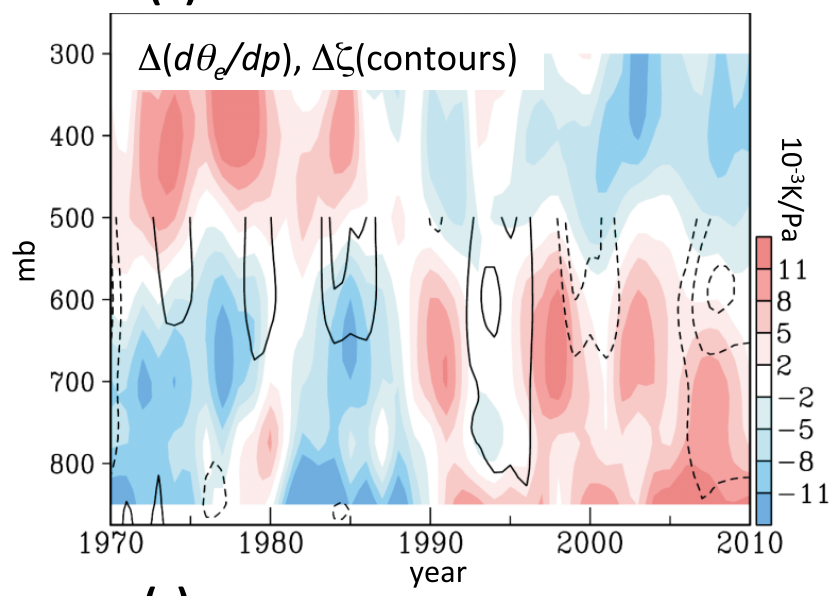

(c)

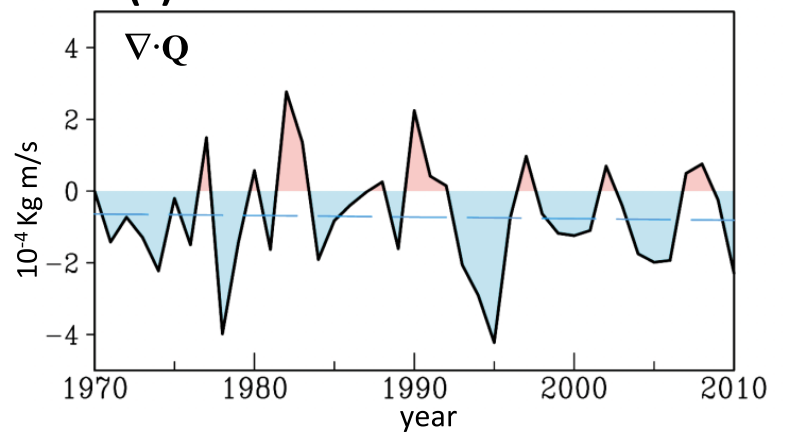

(b)

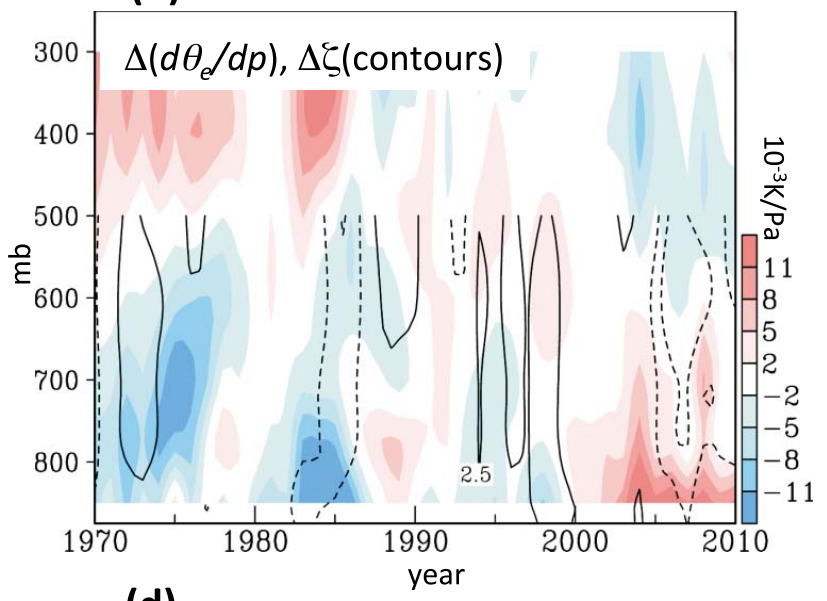

(d)

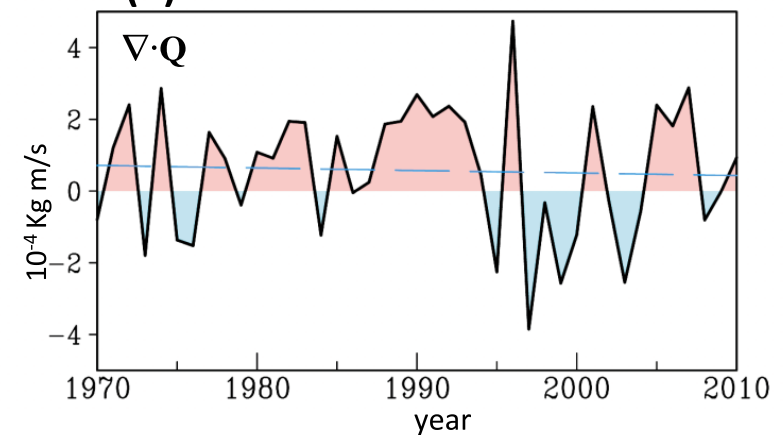

Figure 9. Time-height cross sections of the $\theta_{e}$ lapse rate (shadings) and relative vorticity (contour interval $10^{-5} \mathrm{~s}^{-1}$ omitting zero) averaged over northern Pakistan for (a) July and (b) August, with the longterm means removed, and divergence of water vapor flux (i.e., negative means convergence) during (c) July and (d) August. Linear trends in Figures 9c and 9d) are insignificant (blue dashed lines). 

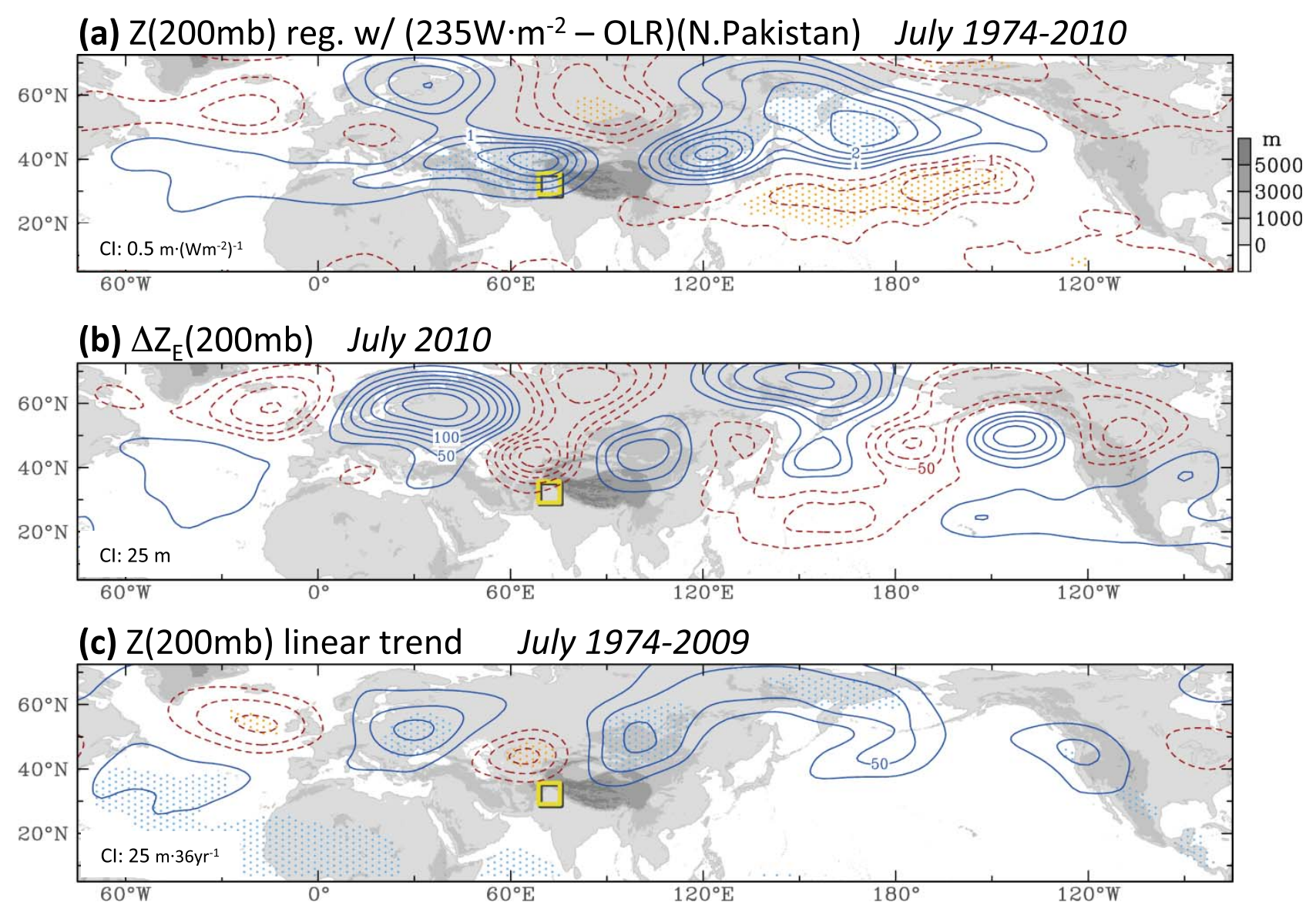

Figure 10. (a) The 200 mbar geopotential height regressed upon $\triangle$ OLR (i.e., 235-OLR) averaged over northern Pakistan (yellow box) for July of 1974-2010, (b) departure of the July 2010 geopotential height from the climatology with the zonal mean removed, and (c) linear trends of the July geopotential height during 1974-2009. Dotted areas in Figures 10a and 10c outline significant regions with the $99 \%$ confidence interval. Background shadings indicate the topography.

interaction. Such an interaction can further enhance conditional instability owing to the combination of high temperature and increased moisture (see Figure 1). Regardless, any empirical model similar to Figure 10a would suggest the cyclonic anomaly in 2010 be associated with a weak monsoon over Pakistan, rather than a strong one. This is alarming because such a departure from the empirical model would have led to false predictions of the monsoon.

[22] Is the 2010 circulation pattern sporadic, or could it be systematic? Figure 10c shows the linear trends of geopotential height over the 1974-2009 period; year 2010 was removed in order to conduct an independent assessment of the trends. The result reveals a zonally oriented wave train that is in phase with the 2010 circulation pattern across the North Atlantic, Eurasia, and East Asia. Trends in the middle and lower-level circulations (not shown) depict consistent phases of this wave train, indicating a barotropic structure. The August circulation anomalies (Figure 11) reveal a similar pattern, i.e., strong monsoon tied with an enhanced anticyclone in the climatology, an opposite situation in 2010, and the cyclonic tendency near northern Pakistan (though the trend is insignificant). However, the cyclonic anomaly in August 2010 (Figure 11b) was further west of Pakistan with an anticyclonic anomaly to the east; this pattern substantiates the wave-like circulation anomalies as perceived from Figures $5 \mathrm{~b}$ and $6 \mathrm{~b}$. Also noteworthy over Eurasia is the anticyclonic tendency that coincides with the 2010 heat wave pattern, suggesting an increased likelihood of similar events over time. Such long-term circulation changes may be associated with the Eurasian warming in recent decades, a phenomenon thought to enhance landocean thermal gradient conducive to a strong monsoon in India [e.g., Kumar et al., 1999]. However, the cause of the transcontinental wave train and its changing relation with the Indian monsoon is complex and requires further analysis.

[23] Trend analysis using a single reanalysis has led to concerns such as changing observation systems [Paltridge et al., 2009]. Hence, to examine whether the long-term trends as revealed in Figures 10c and 11c are spurious, the 1979-2009 trends of July geopotential height, derived from three other reanalyses, are displayed in Figure S2. Apparently the wave train pattern of the trends is consistent between the various reanalyses. Furthermore, we examine 

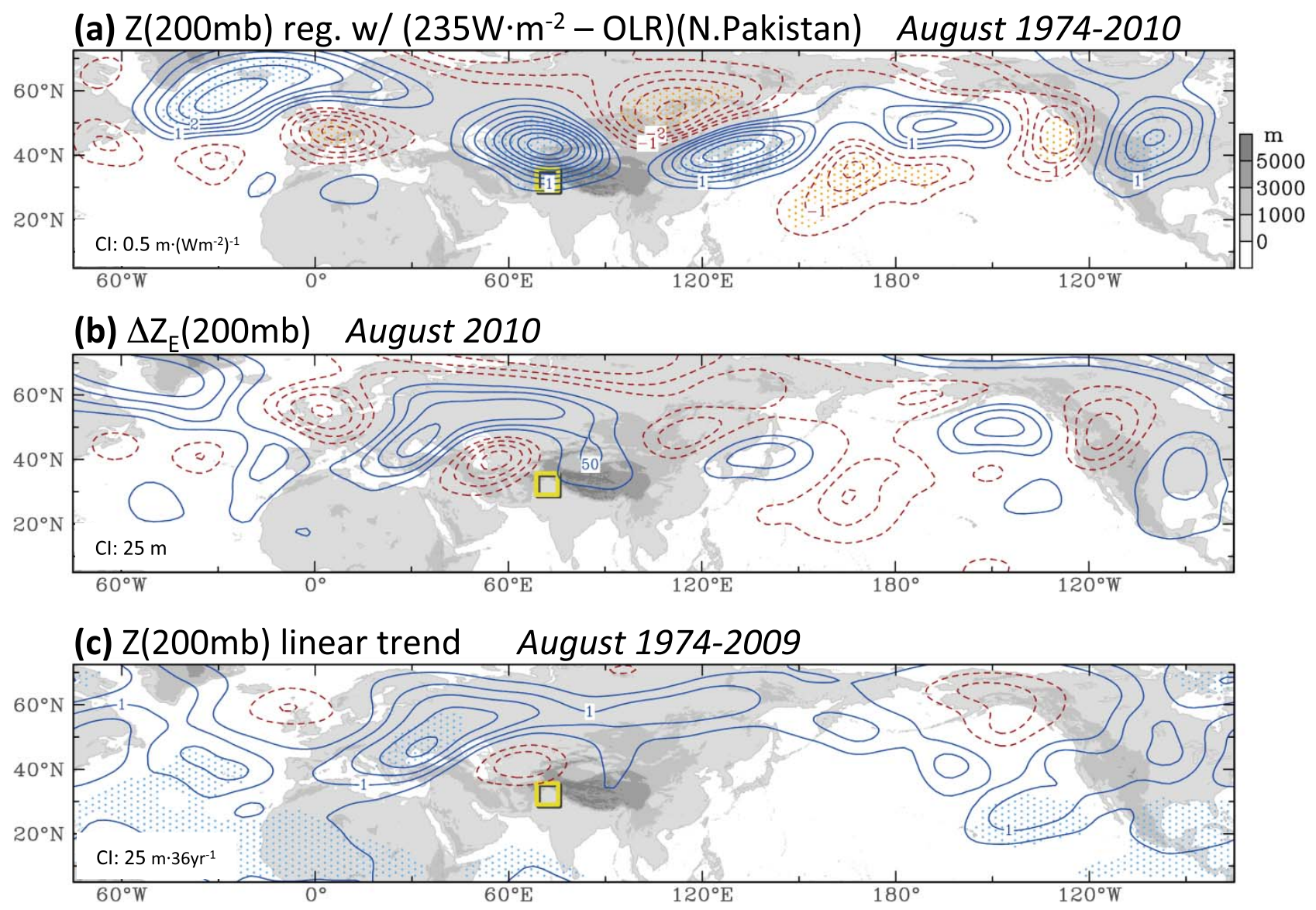

Figure 11. Same as Figure 10 but for August.

trends in the velocity potential (i.e., the divergent circulations) from the four reanalyses, since divergent winds are generally an order smaller than rotational winds and therefore are more sensitive to biases in the reanalyses than firstorder fields such as geopotential height. In order to depict the proper scale of the circumglobal teleconnection, the velocity potential is spatially filtered with zonal wave number 5 and beyond, following Wang et al. [2010]. The results (Figure 12) depict a consistent wave train pattern with upper-level divergence (convergence) situated to the east of the cyclonic (anticyclonic) cells of the wave train in Figure S2. In particular, the divergent center over and to the north of Pakistan suggests an increase in upward mass flux associated with the intensifying trough; this is further evidence to the increase in convective activity in northern Pakistan.

\section{Discussion and Conclusion}

[24] We examined the 2010 summer precipitation in Pakistan, compared to the climatology of this precipitation, and analyzed trends in relevant parameters over the past 40 years, the period of pronounced anthropogenic warming. The analysis suggests that summer precipitation in northern Pakistan comprises two distinct phases: A premonsoon trough phase (July) whose rainfall is more episodic and intense, occurring absent the monsoon trough; and a monsoon trough phase (August) whose rainfall is large but less episodic, driven by northward advancement of the monsoon trough coupled with the 30-60 day mode. The classification here was not intended to redefine the Pakistan monsoon; rather, we have shown that separating the two monsoonal phases helps the detection and attribution of climate change signals.

[25] Long-term trends linking to the 2010 summer rainfall saw an intensification of the premonsoon trough phase only. Analyses of the conditional/potential instability, moisture flux convergence, and circulation features support such intensification as part of a long-term (and ongoing) process, an observation consistent with expectations from a warming and moistening lower troposphere. Conversely, evidence does not support long-term intensification of the August monsoon trough phase in northern Pakistan, nor any trend in the northward extension of the monsoon rainband (other than that accounted for via internal climate variability such as the La Niña and the PDO). Nevertheless, the enhanced convective activity in the premonsoon trough season is manifest in most model projections, indicating a general increase in the intensity of heavy rainfall of the South Asian monsoon [IPCC, 2007].

[26] Large-scale circulation analysis suggests that the typical linkage between increased monsoon rains in northern 

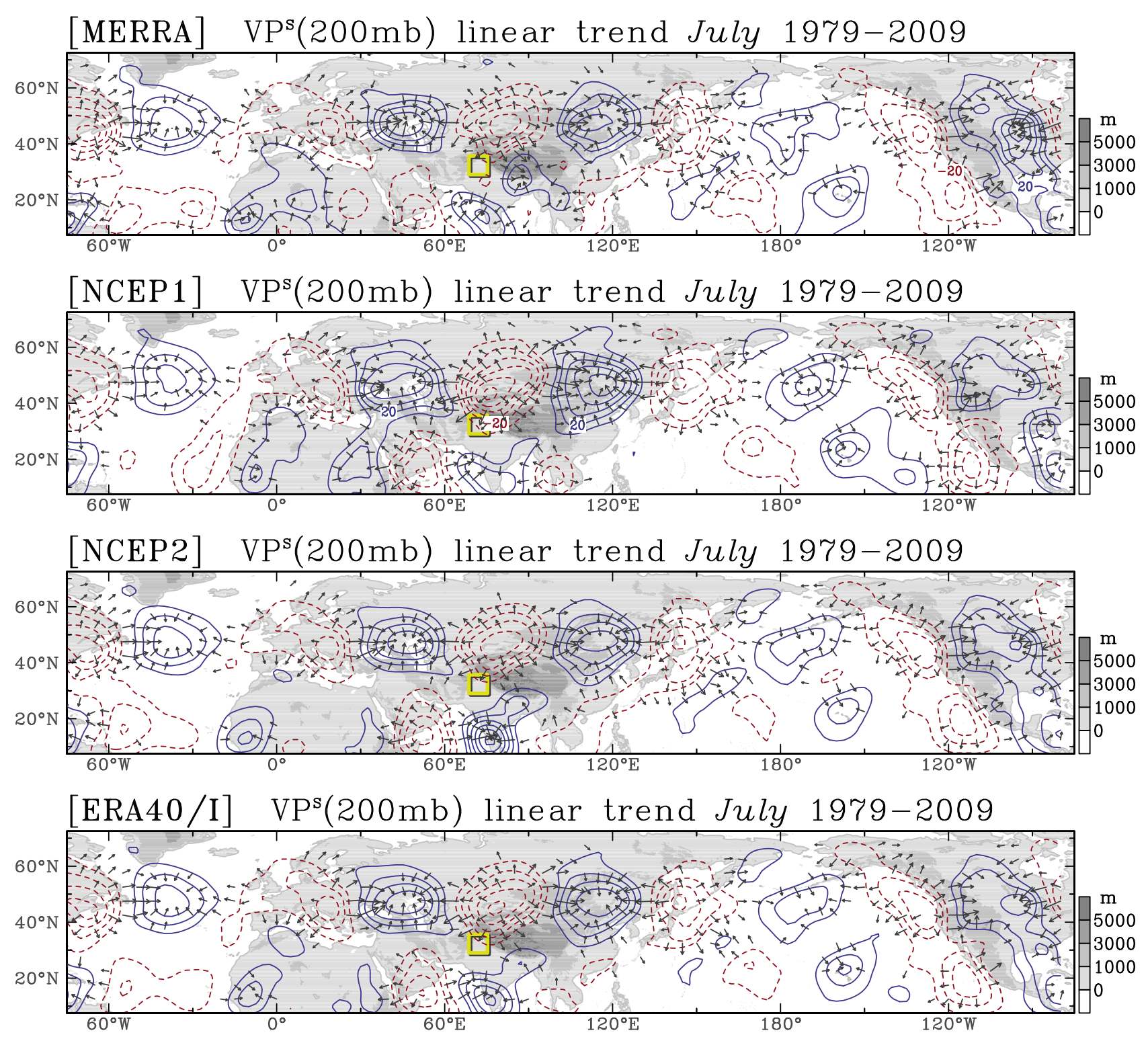

$\mathrm{Cl}: 2 \times 10^{5} \mathrm{~m}^{2} \mathrm{~s}^{-1} \cdot(30 \mathrm{yr})^{-1} \quad \longrightarrow 5 \mathrm{~m} \mathrm{~s}^{-1} \cdot(30 \mathrm{yr})^{-1}$

Figure 12. Same as Figure 10c but for linear trends of the 200 mbar velocity potential spatially filtered with zonal wave number 5 and beyond $\left(\mathrm{VP}^{\mathrm{S}}\right.$ ) during 1979-2009, derived from (top to bottom) the MERRA, NCEP1, NCEP2, and ERA40/Interim reanalyses. The divergent wind vectors are overlaid. The contour interval and the vector scale are given in the bottom. The zero contours are omitted.

Pakistan and enhanced anticyclones at the upper troposphere has changed, in the way that cyclonic anomalies combined with enhanced conditional instability (i.e., due to warming surface and increasing moisture supply) could also trigger intense precipitation, a process substantiated through the unambiguous increase in convective activity. Various global reanalyses come to an agreement that the circulation pattern in July 2010, while abnormal, is not sporadic. Instead, it is part of a long-term trend of the larger-scale circulation that defies the typical monsoon dynamics from which northern Pakistan would expect (i.e., strong monsoons associated with upper-level anticyclones). At this point it is reasonable to conclude that the increased convective activity in northern Pakistan is not only a result of unusual circulation anomalies (i.e., internal variability), but rather is a combined process of circulation changes acting on local destabilization due to warming and moistening of the lower troposphere (i.e., internal + external variabilities). This process may, at least partially, explain the observation by Houze et al. [2011] that "the rainstorms responsible for the floods were of a type that does not normally occur in this region."

[27] Acknowledgments. This study is supported in part by the Utah Agricultural Experiment Station, Utah State University (USU), under paper 8271 and by the USU Livestock-Climate Change Collaborative Research Support Program (CRSP). Comments from three anonymous reviewers were valuable and are highly appreciated. 


\section{References}

Branstator, G. (2002), Circumglobal teleconnections, the jet stream waveguide, and the North Atlantic Oscillation, J. Clim., 15, 1893-1910, doi:10.1175/1520-0442(2002)015<1893:CTTJSW>2.0.CO;2.

Chang, C.-P., and T. N. Krishnamurti (1987), Monsoon Meteorology, 560 pp., Oxford Univ. Press, Oxford, U. K.

Chen, T.-C., J.-H. Yoon, and S.-Y. Wang (2005), Westward propagation of the Indian monsoon depression, Tellus, Ser. A, 57, 758-769.

Christian, H. J., et al. (1999), The lightning imaging sensor, paper presented at 11 th International Conference on Atmospheric Electricity, Int Comm. on Atmos. Electr., Guntersville, Ala.

Ding, Q., and B. Wang (2005), Circumglobal teleconnection in the Northern Hemisphere summer, J. Clim., 18, 3483-3505, doi:10.1175/ JCLI3473.1.

Ding, Q., and B. Wang (2007), Intraseasonal teleconnection between the summer Eurasian wave train and the Indian monsoon, J. Clim., 20, 3751-3767, doi:10.1175/JCLI4221.1.

Ghosh, S., V. Luniya, and A. Gupta (2009), Trend analysis of Indian summer monsoon rainfall at different spatial scales, Atmos. Sci. Lett., 10, 285-290.

Goswami, B. N. (2005), South Asian monsoon, in Intraseasonal Variability in the Atmosphere-Ocean Climate System, edited by W. K. M. Lau and D. E. Waliser, pp. 19-61, Springer, New York, doi:10.1007/3-54027250-X_2.

Goswami, B. N., V. Venugopal, D. Sengupta, M. S. Madhusoodanan, and P. K. Xavier (2006), Increasing trend of extreme rain events over India in a warming environment, Science, 314, 1442-1445, doi:10.1126/science. 1132027.

Hoskins, B. J., and T. Ambrizzi (1993), Rossby wave propagation on a realistic longitudinally varying flow, J. Atmos. Sci., 50, 1661-1671, doi:10.1175/1520-0469(1993)050<1661:RWPOAR >2.0.CO;2.

Houze, R. A., K. L. Rasmussen, S. Medina, S. R. Brodzik, and U. Romatschke (2011), Anomalous atmospheric events leading to the summer 2010 floods in Pakistan, Bull. Am. Meteorol. Soc., 92, 291-298, doi:10.1175/2010BAMS3173.1.

Hussain, M. S., and S. Lee (2009), A classification of rainfall regions in Pakistan, J. Korean Geogr. Soc., 5, 605-623.

Intergovernmental Panel on Climate Change (IPCC) (2007), Regional climate projections, in Climate Change 2007-The Physical Science Basis, chap. 11, pp 881-885, Oxford Univ. Press, Oxford, U. K.

Joyce, R. J., J. E. Janowiak, P. A. Arkin, and P. Xie (2004), CMORPH: A method that produces global precipitation estimates from passive microwave and infrared data at high spatial and temporal resolution, J. Hydrometeorol., 5, 487-503, doi:10.1175/1525-7541(2004) $005<0487$ :CAMTPG $>2.0 . \mathrm{CO} ; 2$.

Kalnay, E., et al. (1996), The NCEP/NCAR 40-Year Reanalysis Project, Bull. Am. Meteorol. Soc., 77, 437-471, doi:10.1175/1520-0477(1996) $077<0437$ :TNYRP $>2.0$. CO;2.

Kanamitsu, M., et al. (2002), NCEP-DOE AMIP-II Reanalysis (R-2), Bull. Am. Meteorol. Soc., 83, 1631-1643, doi:10.1175/BAMS-83-11-1631.

Kazi, S. A. (1951), Climatic regions of West Pakistan, Pak. Geogr. Rev., 6, $1-22$.

Khan, J. A. (1993), The Climate of Pakistan, 79 pp., Rehber, Karachi, Pakistan.

Kodama, Y.-M., A. Ohta, M. Katsumata, S. Mori, S. Satoh, and H. Ueda (2005), Seasonal transition of predominant precipitation type and lightning activity over tropical monsoon areas derived from TRMM observations, Geophys. Res. Lett., 32, L14710, doi:10.1029/2005GL022986.

Kripalani, R. H., A. Kulkarni, S. S. Sabade, and M. L. Khandekar (2003), Indian monsoon variability in a global warming scenario, Nat. Hazards, 29, 189-206, doi:10.1023/A:1023695326825.

Krishnamurti, T. N., and P. Ardunay (1980), The 10-20 day westward propagating model and 'break' in the monsoon, Tellus, 32, 15-26, doi:10.1111/j.2153-3490.1980.tb01717.x.

Krishnamurti, T. N., and D. Subrahmanyam (1982), The 30-50-day mode at $850 \mathrm{mb}$ during MONEX, J. Atmos. Sci., 39, 2088-2095, doi:10.1175/ 1520-0469(1982)039<2088:TDMAMD>2.0.CO;2.

Krishnamurti, T. N., A. Thomas, A. Simon, and V. Kumar (2010), Desert air incursions, an overlooked aspect, for the dry spells of the Indian summer monsoon, J. Atmos. Sci., 67, 3423-3441, doi:10.1175/ 2010JAS3440.1

Krishnan, R., and M. Sugi (2003), Pacific Decadal Oscillation and variability of the Indian summer monsoon rainfall, Clim. Dyn., 21, 233-242, doi: $10.1007 / \mathrm{s} 00382-003-0330-8$.
Kumar, K. K., B. Rajagopalan, and M. A. Cane (1999), On the weakening relationship between the Indian monsoon and ENSO, Science, 284, 2156-2159, doi:10.1126/science.284.5423.2156.

Kureshy, K. U. (1998), Geography of Pakistan, Natl. Book Serv., Lahore, Pakistan.

Marshall, M. (2010), Frozen jet stream links Pakistan floods, Russian fires, New Sci., 2773, 6.

Meehl, G. A., and W. M. Washington (1993), South Asian summer monsoon variability in a model with doubled atmospheric carbon dioxide concentration, Science, 260, 1101-1104, doi:10.1126/science.260. 5111.1101.

Muhammad, J. I. (2005), Detection and modeling of hydrometeorological variability over Pakistan region, $\mathrm{PhD}$. thesis, 196 pp., Inst. of Space and Planet. Astrophys., Univ. of Karachi, Karachi, Pakistan.

Pakistan Meteorological Department (PMD) (2010), Pakistan's Monsoon 2010 update, report, 4 pp., Clim. Data Process. Cent., Karachi, Pakistan. (Available at http://www.pakmet.com.pk/cdpc/prg/monsoon2010/ monsoon2010progress.pdf)

Paltridge, G., A. Arking, and M. Pook (2009), Trends in middle- and upper-level tropospheric humidity from NCEP reanalysis data, Theor. Appl. Climatol., 98, 351-359, doi:10.1007/s00704-009-0117-x.

Patwardhan, S., and H. Bhalme (2001), A study of cyclonic disturbances over India and the adjacent ocean, Int. J. Climatol., 21, 527-534, doi:10.1002/joc.615.

Rienecker, M. M., et al. (2011), MERRA: NASA's modern-era retrospective analysis for research and applications, J. Clim., 24, 3624-3648, doi:10.1175/JCLI-D-11-00015.1.

Schubert, S., H. Wang, and M. Suarez (2010), A MERRA-based analysis of the nature and potential predictability of heat waves and dry spells during boreal summer (6.1), paper presented at 35th Climate Diagnostics and Prediction Workshop, NOAA, Raleigh, N. C.

Singh, O. P. (2001), Long term trends in the frequency of monsoonal cyclonic disturbances over the north Indian Ocean, Mausam, 52, 655-658.

Uppala, S. M., et al. (2005), The ERA-40 re-analysis, Q. J. R. Meteorol. Soc., 131, 2961-3012, doi:10.1256/qj.04.176.

Uppala, S. M., D. Dee, S. Kobayashi, P. Berrisford, and A. Simmons (2008), Towards a climate data assimilation system: Status update of ERA-Interim, ECMWF Newsl., 115, 12-18.

Wang, S.-Y., R. R. Gillies, J. Jin, and L. E. Hipps (2009), Recent rainfall cycle in the Intermountain Region as a quadrature amplitude modulation from the Pacific Decadal Oscillation, Geophys. Res. Lett., 36, L02705, doi:10.1029/2008GL036329.

Wang, S.-Y., L. E. Hipps, R. R. Gillies, X. Jiang, and A. L. Moller (2010), Circumglobal teleconnection and early summer rainfall in the U.S. intermountain west, Theor. Appl. Climatol., 102, 245-252, doi:10.1007/ s00704-010-0260-4.

Wang, S.-Y., R. R. Gillies, L. E. Hipps, and J. Jin (2011), A transitionphase teleconnection of the Pacific quasi-decadal oscillation, Clim. Dyn., 36, 681-693, doi:10.1007/s00382-009-0722-5.

Webster, P. J. (2006), The coupled monsoon system, in The Asian Monsoon, edited by B. Wang, pp. 3-66, Springer, New York.

Webster, P. J., V. E. Toma, and H.-M. Kim (2011), Were the 2010 Pakistan floods predictable?, Geophys. Res. Lett., 38, L04806, doi:10.1029/ 2010GL046346

Xie, P., and P. A. Arkin (1997), Global precipitation: A 17-year monthly analysis based on gauge observations, satellite estimates, and numerical model outputs, Bull. Am. Meteorol. Soc., 78, 2539-2558, doi:10.1175/ 1520-0477(1997)078<2539:GPAYMA>2.0.CO;2.

Xie, P., A. Yatagai, M. Chen, T. Hayasaka, Y. Fukushima, C. Liu, and S. Yang (2007), A gauge-based analysis of daily precipitation over East Asia, J. Hydrometeorol., 8, 607-626, doi:10.1175/JHM583.1.

Yoon, J.-H., and T.-C. Chen (2005), Water vapor budget of the Indian monsoon depression, Tellus, Ser. A, 57, 770-782, doi:10.1111/j.16000870.2005.00145.x

Zhang, C. (1993), Large-scale variability of atmospheric deep convection in relation to sea surface temperature in the tropics, J. Clim., 6, 1898-1913, doi:10.1175/1520-0442(1993)006<1898:LSVOAD>2.0.CO;2.

R. E. Davies, R. R. Gillies, and S.-Y. Wang, Utah Climate Center, Utah State University, 4825 Old Main Hill, Logan, UT 84322-4825, USA. (simon.wang@usu.edu)

W.-R. Huang, Guy Carpenter Asia-Pacific Climate Impact Centre, City University of Hong Kong, 2/F Harbour View 2, 16 Science Park East Ave., Hong Kong Science Park, Shatin, N.T., Hong Kong. 